\title{
Fertility and pregnancy care
}

\section{Kirsten I Black}

\section{THIS EDITION OF Australian Journal of}

General Practice (AJPG) addresses issues of fertility and pregnancy care. In Australia, the maternal mortality ratio has decreased 100-fold since the early 1900s, through improvements in the general health and wellbeing of the population and advances in medical care. ${ }^{1} \mathrm{~A}$ reduction in perinatal mortality of more than sevenfold has also occurred over the same period. Increasingly, it is understood that further improvements in perinatal outcomes and intergenerational health can be achieved by optimising the maternal environment before conception, during pregnancy and in the first two years of a child's life. ${ }^{2}$

The term 'first 1000 days' was coined in 2010, at the World Bank headquarters in Washington DC, at a gathering of developmental experts who were looking at how best to address the issue of undernutrition in low-resource settings. ${ }^{3}$ The developing fetus and infant are at their most adaptable and most vulnerable during the first 1000 days. From the time of conception, the fetus reacts to environmental changes and is able to adapt in response to signals provided by the mother's physical and mental state. ${ }^{2}$ This powerful capacity is both a blessing and a curse, as adapting to adverse events may be beneficial in the short term but have negative implications in the long term. There is limited community and professional understanding of the significance of the first 1000 days; our health system in Australia is often focused on acute rather than preventive care, and pregnancy planning is not widely adopted. Studies on antenatal patients in Australia have found that only $50 \%$ plan their pregnancies. $^{4}$

The Centre for Community Child Health in Melbourne was recently part of an alliance that summarised the evidence for the importance of the first 1000 days in a paper. ${ }^{5}$ The key messages incorporate notions of the developmental origins of health and disease, as well as the broader social determinants of health and the inherent drawbacks of modern urban living. Preconception lifestyle modification, pregnancy planning and weight loss are excellent ideas but may not always be feasible or logistically possible. The most promising approaches to improve the lived environment for all are multilevel and focus on policy change, with participation from actors in multiple sectors. ${ }^{6}$

Articles in this edition of AJGP discuss preconception care, ${ }^{7}$ recurrent miscarriage, ${ }^{8}$ gestational diabetes mellitus (GDM) ${ }^{9}$ and pelvic pain. ${ }^{10}$ Recurrent miscarriage is on the rise; one Swedish study showed an increase in recurrent miscarriages from 42 per 100,000 women aged 18-42 in 2003 to 73 per 100,000 women in 2012. The authors postulated that environmental and immunological changes in people's lives have had a significant impact on this increase. ${ }^{11}$ GDM is also on the rise in Australia, affecting $12-15 \%$ of women in the second trimester of pregnancy. ${ }^{12}$ Risk factors for GDM are similar to those of recurrent miscarriage and include older age, obesity and polycystic ovarian syndrome. ${ }^{13} \mathrm{Good}$ management is crucial for the prevention of long-term health issues for the mother and the child. Pelvic pain in pregnancy can be suboptimally managed by health professionals and can affect the mobility and quality of life for women during pregnancy and beyond.

In many respects, we have world-class care in Australia for pregnant women. However, the challenge ahead is to recognise the broader context of women's lives and integrate public policies on health and the environment, to enable communities to make choices that will improve the short-term and long-term outcomes for women and their children. We are taking the first step in Australia by recognising the significance of the first 1000 days, but this is yet to be promoted in national strategies. Small investments in this field have the potential for great gains, and we should be supporting the concept of the continuum of care that is promoted in low-resource settings.

\section{Author}

Kirsten I Black MBBS, MMed, FRANZCOG, DDu, $\mathrm{PhD}, \mathrm{MFSRH}$ is joint head of the Discipline of Obstetrics, Gynaecology and Neonatology at the University of Sydney, NSW.

\section{References}

1. de Looper MW. Death registration and mortality trends in Australia 1856-1906. Canberra: ANU, 2014

2. Karakochuk CD, Whitfield KC, Green TJ, Kraemer K, eds. The biology of the first 1,000 days. Florida: Taylor \& Francis Group, 2017.

3. Thurow R. The first 1,000 days: A crucial time for mother and children - And the world. New York: PublicAffairs, 2016.

4. Rassi A, Wattimena J, Black K. Pregnancy intention in an urban Australian antenatal population. Aust N Z J Public Health 2013;37(6):568-73.

5. Moore TG, Arefadib N, Deery A, Keyes M, West S. The first thousand days: An evidence paper Summary. Melbourne: Murdoch Children's Research Institute, 2017

6. Institute of Medicine (US) Committee on an Evidence Framework for Obesity Prevention Decision Making. Obesity Prevention Strategies in Concept and Practice. In: Kumanyika SK, Parker L, Sim LJ, eds. Bridging the evidence gap in obesity prevention: A framework to inform decision making. Washington DC: National Academies Press, 2010.

7. Dorney E, Black K. Preconception care. Aust J Gen Pract 2018;47(7):424-29.

8. Li YH, Marren A. Recurrent pregnancy loss: A summary of international evidence-based guidelines and practice. Aust J Gen Pract 2018;47(7):432-36.

9. Nankervis A, Price S, Conn J. Gestational diabetes: A pragmatic approach to diagnosis and management. Aust J Gen Pract 2018;47(7):445-49.

10. Walters $C$, West $S$, Nippita T. Pelvic girdle pain in pregnancy. Aust J Gen Pract 2018;47(7):439-43.

11. Rasmark Roepke E, Matthiesen L, Rylance R, Christiansen OB. Is the incidence of recurrent pregnancy loss increasing? A retrospective register-based study in Sweden. Acta Obstet Gynecol Scand 2017;96(11):1365-72. doi: 10.1111/ aogs.13210.

12. National Diabetes Services Scheme. Gestational diabetes. ACT: NDSS, 2018. Available at www. ndss.com.au/gestational-diabetes [Accessed 10 May 2018]

13. Chakraborty P, Goswami SK, Rajani S, et al. Recurrent pregnancy loss in polycystic ovary syndrome: Role of hyperhomocysteinemia and insulin resistance. PLoS One 2013;8(5):e64446. doi: 10.1371/journal.pone.0064446.

correspondence ajgp@racgp.org.au 